\title{
Impulsivity and overeating: a closer look at the subscales of the Barratt Impulsiveness Scale
}

\author{
Adrian Meule* \\ Department of Psychology I, University of Würzburg, Würzburg, Germany \\ *Correspondence: adrian.meule@uni-wuerzburg.de \\ Edited by: \\ Astrid Müller, Hannover Medical School, Germany \\ Reviewed by: \\ Laurence J. Nolan, Wagner College, USA
}

Impulsivity can be defined as a predisposition toward rapid, unplanned reactions to internal or external stimuli regardless of negative consequences of these reactions for the impulsive individual or for others (Moeller et al., 2001). It is a multifaceted construct and there is a range of methods available for its measurement. Two of the most often used methods are selfreport instruments and behavioral tasks (e.g., go/no-go tasks and delay discounting tasks). Self-reported impulsivity is positively correlated with impulsive reactions in behavioral measures, yet correlations are often weak and inconsistent (Logan et al., 1997; Lijffijt et al., 2004; Enticott et al., 2006; Reynolds et al., 2006; Cyders and Coskunpinar, 2011). It is assumed that self-report questionnaires represent impulsivity as a stable trait while behavioral tasks are subject to state-dependent variations. Nonetheless, both self-report and behavioral measures indicate that high impulsivity is a risk factor for a range of maladaptive behaviors, including overor binge eating (Guerrieri et al., 2008; Waxman, 2009).

Beyond the fact that self-report and behavioral measures seem to capture different aspects of impulsivity, conceptualizations also vary between the different self-report instruments. For instance, two of the most widely used impulsivity questionnaires are the UPPS Impulsive Behavior Scale (Whiteside and Lynam, 2001) and the Barratt Impulsiveness Scale (BIS-11, Patton et al., 1995). The UPPS assesses impulsivity on the subscales urgency (acting rashly under conditions of negative affect), lack of premeditation (difficulty in thinking and reflecting on consequences of an act), lack of perseverance (inability to remain focused on a task), and sensation seeking (tendency and openness to try and enjoy exciting or dangerous activities). The BIS-11 assesses impulsivity on the subscales attentional impulsivity (inability to focus attention or concentrate), motor impulsivity (acting without thinking), and non-planning impulsivity (lack of future orientation or forethought). Both questionnaires are highly correlated with each other $(r=0.67)$, but correlations between their subscales are only weak and inconsistent, supporting the notion that both measures cover different aspects of impulsivity (Meule et al., 2011). Beyond using the UPPS total score, relationships between UPPS subscales and eating behavior have been investigated and it has been found that urgency in particular is predictive for eating problems, e.g., binge eating (Fischer et al., 2003, 2008; Smith et al., 2007; Mobbs et al., 2008; Manwaring et al., 2011; Dir et al., 2013). To date, similar clear-cut results for the BIS-11 are missing. Although it is widely used, most studies only use its total score for analysis. In this brief opinion piece I would like to advocate the use of BIS-subscales. That is, researchers may benefit from examining relationships between BIS-subscales and eating behavior in greater detail.

Only a few studies have done this as yet. For instance, differential relationships between subscales of the BIS-11 and eating disorder symptomatology have been found in clinical samples. Patients with binge eating disorder had higher scores on the motor impulsivity subscale compared to healthy controls, but did not differ on the other two subscales (Nasser et al., 2004). Two studies compared scores on the BIS-11 between patients with bulimia nervosa (BN), anorexia nervosabinge/purge type (AN-BP), anorexia nervosa-restrictive type (AN-R), and healthy controls. In a first study by Rosval and colleagues (2006), eating disorder groups did not differ from each other on the attentional impulsivity subscale, but all had higher scores than controls. With regard to motor impulsivity, the two groups with binge eating behavior (BN and AN-BP) had higher scores than both the AN-R group and controls. The $\mathrm{BN}$ group also had higher scores on nonplanning impulsivity than both the AN-BP and AN-R group, but did not differ from controls (Rosval et al., 2006). In a second study (Claes et al., 2006), the two groups with binge eating (BN and AN-BP) reported higher attentional impulsivity compared to controls. With regard to motor impulsivity, $\mathrm{AN}-\mathrm{BP}, \mathrm{BN}$, and controls had higher scores than AN-R. The $\mathrm{BN}$ group and controls also had higher scores on non-planning impulsivity than AN-R (Claes et al., 2006). In sum, it appears that eating disorder patients with binge eating behaviors have higher BIS-11 scores, particularly on its motor and attentional impulsivity subscales, compared to patients with restrictive eating behavior and controls.

Studies investigating non-clinical samples also revealed differential associations between BIS-11 subscales and various measures of eating behavior. For example, Lyke and Spinella (2004) examined the associations between the BIS-11 and the Eating Inventory (formerly Three-Factor Eating Questionnaire, Stunkard and Messick, 1985). A small positive correlation was found between the hunger subscale and attentional impulsivity. Furthermore, both attentional and motor impulsivity were correlated with disinhibition (Lyke and Spinella, 2004). 
There was a small positive association between non-planning impulsivity and rigid control of eating behavior in female, but not male, students (Timko and Perone, 2005).

In a recent study by van Koningsbruggen and colleagues (2013), only the attentional impulsivity subscale of the BIS-11, but not the other two subscales, was positively correlated with the concern for dieting subscale of the Restraint Scale (Herman and Mack, 1975). In addition, both attentional and non-planning impulsivity were negatively related to selfperceived dieting success. With regard to body-mass-index (BMI), there was a positive correlation with the motor impulsivity subscale (van Koningsbruggen et al., 2013). In a study by Nolan (2012), female students were asked to rate the pleasantness of eating different foods on a visual analog scale and to complete the BIS-11. Only the attentional impulsivity subscale, but not the other two subscales, was positively correlated with the pleasantness of eating high-calorie foods like French fries, pasta, and pizza. No correlations between the BIS-11 and BMI could be found (Nolan, 2012). In a sample of pathological gamblers (von Ranson et al., 2013), only the attentional subscale of the
BIS-11, but not the other two subscales, was positively correlated with the eating concern subscale of the Eating Disorder Examination-Questionnaire (Fairburn and Beglin, 1994).

While the BIS-11 contains 30 items, Spinella (2007) developed a short form of the BIS-11 which consists of 15 items only (BIS-15). The three-factorial structure of the long version could also be found using the short form and each subscale contains five items (Spinella, 2007; Meule et al., 2011). Scores of the short form are highly correlated with the full version $(r=0.94$, Spinella, 2007).

In a range of studies, positive correlations could be found between the BIS15 and various constructs that are related to overeating (Table 1), e.g., frequent and intense experiences of food cravings (Food Cravings Questionnaire-Trait, Cepeda-Benito et al., 2000), emotional eating (Mood Eating Scale, Jackson and Hawkins, 1980), night eating (Night Eating Questionnaire, Allison et al., 2008), low dieting success (Perceived Self-Regulatory Success in Dieting Scale, Meule et al., 2012e), restrained eating (Restraint Scale, Herman and Mack, 1975), and food addiction symptomatology (Yale Food Addiction Scale, Gearhardt et al., 2009). It appears that associations with those measures were particularly observed for the attentional impulsivity subscale while there were no or only negligible relationships with the other subscales in both student samples and severely obese candidates for bariatric surgery (Table 1). Notably, BMI was rarely correlated with the BIS-15 and in some instances correlations were even negative (Table 1).

Up to now, only one other research group has examined relations between eating behavior measures and BIS-15 subscales. In this study (Hou et al., 2011), the attentional and motor subscale of the BIS-15, but not the non-planning subscale, were positively correlated with the external eating subscale of the Dutch Eating Behavior Questionnaire (van Strien et al., 1986) and with attentional bias toward high-calorie foods as measured with a visual probe task. In addition, partial correlations revealed that attentional impulsivity mediated the association between external eating and attentional bias (Hou et al., 2011).

In sum, it appears that attentional impulsivity is most consistently related to various measures that are associated with overeating. Positive, but less consistent, relationships can also be found with

Table 1 | Correlations between the Barratt Impulsiveness Scale-short form, body-mass-index, and various self-report measures associated with overeating.

\begin{tabular}{|c|c|c|c|c|}
\hline & \multicolumn{4}{|c|}{ Barratt Impulsiveness Scale-short form } \\
\hline & Attentional & Motor & Non-planning & Total score \\
\hline \multicolumn{5}{|l|}{ STUDENT SAMPLES } \\
\hline Body-mass-index $\left(\mathrm{kg} / \mathrm{m}^{2}\right)^{1,2,3,4,5,6}$ & -0.03 to 0.19 & -0.15 to 0.11 & -0.10 to 0.20 & -0.09 to 0.15 \\
\hline Food Cravings Questionnaire-Trait $2,4,5,6$ & 0.26 to $\mathbf{0 . 3 8}$ & 0.07 to 0.23 & -0.05 to 0.08 & 0.13 to 0.28 \\
\hline Mood Eating Scale ${ }^{4}$ & 0.30 & 0.18 & 0.03 & 0.23 \\
\hline Night Eating Questionnaire 4 & 0.32 & 0.15 & 0.11 & 0.26 \\
\hline $\begin{array}{l}\text { Perceived Self-Regulatory Success in } \\
\text { Dieting }^{2,3,5,6}\end{array}$ & $-\mathbf{0 . 3 6}$ to -0.20 & 0.01 to 0.11 & -0.04 to 0.04 & -0.14 to -0.06 \\
\hline Restraint Scale $3,5,6$ & 0.22 to 0.26 & -0.01 to 0.12 & -0.13 to 0.05 & 0.02 to 0.20 \\
\hline $\begin{array}{l}\text { Yale Food Addiction Scale-symptom } \\
\text { count } 1,2,3,6\end{array}$ & 0.22 to $\mathbf{0 . 3 4}$ & 0.06 to 0.15 & 0.00 to 0.13 & 0.12 to 0.26 \\
\hline \multicolumn{5}{|l|}{ BARIATRIC PATIENTS ${ }^{7}$} \\
\hline Body-mass-index $\left(\mathrm{kg} / \mathrm{m}^{2}\right)$ & -0.23 & -0.03 & -0.24 & -0.22 \\
\hline $\begin{array}{l}\text { Eating Disorder Examination-Questionnaire- } \\
\text { objective binge episodes }\end{array}$ & 0.38 & 0.04 & 0.10 & 0.23 \\
\hline Food Cravings Questionnaire-Trait & 0.45 & 0.10 & 0.09 & 0.27 \\
\hline Yale Food Addiction Scale-symptom count & 0.39 & 0.11 & 0.11 & 0.26 \\
\hline
\end{tabular}

Notes: Numbers in boldface indicate correlations $\geq 0.3$. Note that $p$-values are not reported because of different sample sizes.

${ }^{1}$ (Meule et al., 2012f) ( $\left.n=752\right),{ }^{2}$ (Meule et al., 2012c) ( $\left.n=616\right),{ }^{3}$ (Meule et al., 2012d) ( $\left.n=50\right),{ }^{4}$ (Meule et al., 2012a) ( $\left.n=729\right),{ }^{5}$ unpublished data ( $\left.n=55\right)$,

${ }^{6}$ unpublished data $(n=51),{ }^{7}$ (Meule et al., 2012b) ( $\left.n=81\right)$. 
motor impulsivity, particularly in patients with binge eating behavior. Non-planning impulsivity seems to be only weakly related to overeating. Neither subscale seems to be consistently correlated with BMI, which may be due to the fact that BMI is influenced by many factors other than eating behavior. Future research needs to address the question why attentional impulsivity in particular has such a prominent role in overeating. First evidence suggests that attentional impulsivity may increase the susceptibility that highly palatable food-cues attract attention and trigger eating behavior (Hou et al., 2011). The exact mechanisms, however, are yet to be determined. For example, food-cue induced overeating may be the result of overwhelming, reward-related, bottom-up processes or deficient inhibitory, top-down control mechanisms, or both (Appelhans, 2009; Heatherton and Wagner, 2011). In line with this, it may be that there are also interactive effects of BIS-subscales on overeating which have not been considered in past research. For example, high attentional impulsivity may be related to moderate overeating through rewardsensitive mechanisms (Nolan, 2012), but may be particularly crucial in combination with high motor impulsivity, indicating low inhibitory control. Thus, the use of the BIS-subscales and their interactions has the potential to contribute to the understanding of mechanisms underlying overeating.

\section{ACKNOWLEDGMENTS}

The author would like to thank Petra Platte for proofreading the first draft of this manuscript.

\section{REFERENCES}

Allison, K. C., Lundgren, J. D., O’Reardon, J. P., Martino, N. S., Sarwer, D. B., Wadden, T. A., et al. (2008). The Night Eating Questionnaire (NEQ): psychometric properties of a measure of severity of the Night Eating Syndrome. Eat. Behav. 9, 62-72.

Appelhans, B. M. (2009). Neurobehavioral inhibition of reward-driven feeding: implications for dieting and obesity. Obesity 17, 640-647.

Cepeda-Benito, A., Gleaves, D. H., Williams, T. L., and Erath, S. A. (2000). The development and validation of the state and trait Food-Cravings Questionnaires. Behav. Ther. 31, 151-173.

Claes, L., Nederkoorn, C., Vandereycken, W., Guerrieri, R., and Vertommen, H. (2006). Impulsiveness and lack of inhibitory control in eating disorders. Eat. Behav. 7, 196-203.
Cyders, M. A., and Coskunpinar, A. (2011). Measurement of constructs using self-report and behavioral lab tasks: Is there overlap in nomothetic span and construct representation for impulsivity? Clin. Psychol. Rev. 31, 965-982.

Dir, A. L., Karyadi, K., and Cyders, M. A. (2013). The uniqueness of negative urgency as a common risk factor for self-harm behaviors, alcohol consumption, and eating problems. Addict. Behav. 38, 2158-2162.

Enticott, P. G., Ogloff, J. R. P., and Bradshaw, J. L. (2006). Associations between laboratory measures of executive inhibitory control and self-reported impulsivity. Pers. Indiv. Differ. 41, 285-294.

Fairburn, C. G., and Beglin, S. J. (1994). Assessment of eating disorders: interview or self-report questionnaire? Int. J. Eat. Disord. 16, 363-370.

Fischer, S., Smith, G. T., and Anderson, K. G. (2003). Clarifying the role of impulsivity in bulimia nervosa. Int. J. Eat. Disord. 33, 406-411.

Fischer, S., Smith, G. T., and Cyders, M. A. (2008). Another look at impulsivity: a meta-analytic review comparing specific dispositions to rash action in their relationship to bulimic symptoms. Clin. Psychol. Rev. 28, 1413-1425.

Gearhardt, A. N., Corbin, W. R., and Brownell, K. D. (2009). Preliminary validation of the Yale Food Addiction Scale. Appetite 52, 430-436.

Guerrieri, R., Nederkoorn, C., and Jansen, A. (2008). The effect of an impulsive personality on overeating and obesity: current state of affairs. Psychol. Top. 17, 265-286.

Heatherton, T. F., and Wagner, D. D. (2011). Cognitive neuroscience of self-regulation failure. Trends Cogn. Sci. 15, 132-139.

Herman, C. P., and Mack, D. (1975). Restrained and unrestrained eating. J. Pers. 43, 647-660.

Hou, R., Mogg, K., Bradley, B. P., Moss-Morris, R., Peveler, R., and Roefs, A. (2011). External eating, impulsivity and attentional bias to food cues. Appetite 56, 424-427.

Jackson, L. J., and Hawkins, R. C. 2nd. (1980). “Stressrelated overeating among college students: development of a mood eating scale," Paper Presented at the 26th Annual Convention of the Southwestern Psychological Association (Oklahoma City, OK).

Lijffijt, M., Bekker, E. M., Quik, E. H., Bakker, J., Kenemans, J. L., and Verbaten, M. N. (2004). Differences between low and high trait impulsivity are not associated with differences in inhibitory motor control. J. Atten. Disord. 8, 25-32.

Logan, G. D., Schachar, R. J., and Tannock, R. (1997). Impulsivity and inhibitory control. Psychol. Sci. 8, 60-64.

Lyke, J. A., and Spinella, M. (2004). Associations among aspects of impulsivity and eating factors in a nonclinical sample. Int. J. Eat. Disord. 36, 229-233.

Manwaring, J. L., Green, L., Myerson, J., Strube, M. J., and Wilfley, D. E. (2011). Discounting of various types of rewards by women with and without binge eating disorder: evidence for general rather than specific differences. Psychol. Rec. 61, 561-582.

Meule, A., Baumbusch, D., Allison, K., Stunkard, A., and Platte, P. (2012a). A German version of the Night Eating Questionnaire (NEQ): prevalence and correlates of night eating syndrome. Obes. Facts 5, 21.

Meule, A., Heckel, D., and Kübler, A. (2012b). Factor structure and item analysis of the Yale Food Addiction Scale in obese candidates for bariatric surgery. Eur. Eat. Disord. Rev. 20, 419-422.

Meule, A., Lutz, A., Vögele, C., and Kübler, A. (2012c). Food cravings discriminate differentially between successful and unsuccessful dieters and non-dieters. Validation of the food craving questionnaires in German. Appetite 58, 88-97.

Meule, A., Lutz, A., Vögele, C., and Kübler, A. (2012d). Women with elevated food addiction symptoms show accelerated reactions, but no impaired inhibitory control, in response to pictures of high-calorie food-cues. Eat. Behav. 13, 423-428.

Meule, A., Papies, E. K., and Kübler, A. (2012e). Differentiating between successful and unsuccessful dieters: validity and reliability of the perceived self-regulatory success in dieting scale. Appetite 58, 822-826.

Meule, A., Vögele, C., and Kübler, A. (2012f). German translation and validation of the Yale Food Addiction Scale. Diagnostica 58, 115-126.

Meule, A., Vögele, C., and Kübler, A. (2011). Psychometric evaluation of the German Barratt Impulsiveness Scale-Short Version (BIS-15). Diagnostica 57, 126-133.

Mobbs, O., Ghisletta, P., and Van Der Linden, M. (2008). Clarifying the role of impulsivity in dietary restraint: a structural equation modeling approach. Pers. Indiv. Differ. 45, 602-606.

Moeller, F. G., Barratt, E. S., Dougherty, D. M., Schmitz, J. M., and Swann, A. C. (2001). Psychiatric aspects of impulsivity. Am. J. Psychiatry 158, 1783-1793.

Nasser, J. A., Gluck, M. E., and Geliebter, A. (2004). Impulsivity and test meal intake in obese binge eating women. Appetite 43, 303-307.

Nolan, L. J. (2012). Association between impulsiveness and pleasantness ratings for food and drugs. Appetite 59, e43.

Patton, J. H., Stanford, M. S., and Barratt, E. S. (1995). Factor structure of the Barratt Impulsiveness Scale. J. Clin. Psychol. 51, 768-774.

Reynolds, B., Ortengren, A., Richards, J. B., and De Wit, H. (2006). Dimensions of impulsive behavior: personality and behavioral measures. Pers. Indiv. Differ. 40, 305-315.

Rosval, L., Steiger, H., Bruce, K., Israël, M., Richardson, J., and Aubut, M. (2006). Impulsivity in women with eating disorders: problem of response inhibition, planning, or attention? Int. J. Eat. Disord. 39, 590-593.

Smith, G. T., Fischer, S., Cyders, M. A., Annus, A. M., and Spillane, N. S. (2007). On the validity and utility of discriminating among impulsivity-like traits. Assessment 14, 155-170.

Spinella, M. (2007). Normative data and a short form of the barratt impulsiveness scale. Int. J. Neurosci. 117, 359-368.

Stunkard, A. J., and Messick, S. (1985). The threefactor eating questionnaire to measure dietary restraint, disinhibition and hunger. J. Psychosom. Res. 29, 71-83. 
Timko, C. A., and Perone, J. (2005). Rigid and flexible control of eating behavior in a college population. Eat. Behav. 6, 119-125.

van Koningsbruggen, G. M., Stroebe, W., and Aarts, H. (2013). Successful restrained eating and trait impulsiveness. Appetite 60, 81-84.

von Ranson, K. M., Wallace, L. M., Holub, A., and Hodgins, D. C. (2013). Eating disorders, substance use disorders, and impulsiveness among disordered gamblers in a community sample. Eur. Eat. Disord. Rev. 21, $148-154$. van Strien, T., Frijters, J. E. R., Bergers, G. P. A., and Defares, P. B. (1986). The Dutch Eating Behavior Questionnaire (DEBQ) for assessment of restrained, emotional, and external eating behavior. Int. J. Eat. Disord. 5, 295-315.

Waxman, S. E. (2009). A systematic review of impulsivity in eating disorders. Eur. Eat. Disord. Rev. 17, 408-425.

Whiteside, S. P., and Lynam, D. R. (2001). The five factor model and impulsivity: using a structural model of personality to understand impulsivity. Pers. Indiv. Differ. 30, 669-689.
Received: 07 March 2013; accepted: 25 March 2013; published online: 10 April 2013.

Citation: Meule A (2013) Impulsivity and overeating: $a$ closer look at the subscales of the Barratt Impulsiveness Scale. Front. Psychol. 4:177. doi: 10.3389/fpsyg. 2013.00177

This article was submitted to Frontiers in Eating Behavior, a specialty of Frontiers in Psychology.

Copyright (c) 2013 Meule. This is an open-access article distributed under the terms of the Creative Commons Attribution License, which permits use, distribution and reproduction in other forums, provided the original authors and source are credited and subject to any copyright notices concerning any third-party graphics etc. 